\title{
Role of AOA Sensor and MCAS Activation in Boeing Max 8 Flights - A Case Study of Lion Air JT610 and Ethiopian Airlines ET302
}

\author{
Engr. Minu Theresa Mathew ${ }^{1}$, Zeyad M. Ismail ${ }^{2}$ \\ Faculty, College of Engineering, AMA University, Manama, Bahrain ${ }^{1}$ \\ Associate Professor, College of Engineering, AMA University, Manama, Bahrain ${ }^{2}$
}

\begin{abstract}
This study mainly focuses on the role of Angle of Attack (AOA) Sensor and Manuevering Characteristics Augmentation System (MCAS) in a Boeing Max 8 Flights which are involved in the crashes of Lion Air JT610 and Ethiopian Airlines ET302. The flight data recorder readings and other statistical readings of these involved flights is analysed to conclude the role of AOA Sensor and MCAS System. MCAS which is known as Manuevering Characteristics Augmentation System is a sensor based Algorithm which will keep the nose of the plane down depending on the inputs of two or either one of the two AOA Sensors deployed. An in-depth understanding of in-flight MCAS and how it was behaving in both flights, JT610 and ET302, is analysed in this study.
\end{abstract}

Keywords: AOA Sensor, Manuevering Characteristics Augmentation System (MCAS), Lion air JT610 and Ethiopian air ET302

MCAS System: A Maneuvering Characteristics Augmentation System, automated algorithm implemented in the aircraft which is actively on when the pitch angle is more than critical angle

\section{INTRODUCTION}

In the present era aircraft industry is a booming field with millions of people flying from place to place. Safety is not an option in high performance commercial jets since; airline business is centered on the concept of safety first slogan. There should be a directive which can be an airworthiness one to effectively implement the performance of airline safety mechanisms. Boeing is a leading commercial jet manufacturing company based in United States. The latest air fleet to their new generation commercial fleet is Max aircrafts, which is claimed to have improved efficiency in terms of fuel, different wing designs, advanced safety features like the MCAS system, improved fuselage with better interiors better engine and less noise etc. But the real question in the wake of the recent fatal crashes of Boeing 737 Max 8 is that are these planes prioritizing safety? And the question of safety first is it really followed in the design of these aircrafts?. The study [1] focuses on the explanation of the Boeing 737 max system MCAS System and electric trim override operation of the system which was supposed to be a safety feature in the Boeing 737 Max 8 flight. The study also suggests that the manual overriding of the MCAS System is possible in the cockpit by the pilot. The Boeing system is designed such that the MCAS will be activated when the angle of attack is greater than a suitable threshold and stabilizer trim nose down command will be activated under the erroneous reading range. Paper [2] deals with the many factors that caused the crash of the airlines, especially Boeing 737 Max 8. The main human errors and mechanical errors concerning the crash were also discussed in this paper. Paper[3] discusses about the legacy of 737 series of air fleet and the fact that Max series was actually built on a decade old system of 737 series fleets. The aerodynamics of the plane was such that there was a good possibility of stall conditions of the aircrafts under different air speeds. Owing to the stall factor the engine of the fleets were raised to avoid stalling. The article also focuses on the response time of Lion air JT610 was only 40 seconds to respond to the emergency. Paper [4] focuses on many manual factors involved in the crash and a comprehensive study of MCAS activation.

\section{RESEARCH METHODOLOGY}

\section{A. Statement of the problem}

Boeing has introduced the new generation Max 8 aircrafts which has bigger engines that are uplifted and situated a bit forward compared to other 737 series air fleets, where as in the other new generation aircrafts the engines are flat compared to Max series. MCAS system is implemented in Max 8 aircrafts because the higher and forward engines can make the nose of the aircraft up. This pitching up can be detected by an Angle of Attack sensor (AOA) situated very 


\title{
International Advanced Research Journal in Science, Engineering and Technology
}

\author{
Vol. 6, Issue 5, May 2019
}

near to the nose of the aircraft. The AOA sensor is aligned in the direction of airstream. Depending on the reading of the AOA sensor, the MCAS system algorithm forces the horizontal stabilizer in the upward direction, making the nose of the aircraft down to reduce the pitch and prevent stalling. Now the MCAS system can be manually incapacitated by the pilot in the cockpit by just turning off a switch, but the system can be problematic if the AOA sensor reading is erroneous which means manual turning off will not be enough as the AOA sensor continues to give faulty readings the nose of the aircraft will continuously pitched down causing a rift between pilots manual action and maneuvering system of the aircraft which can be disastrous. The MCAS system activation is of sufficient importance because the activation happens after engaging of autopilot and flight flaps being in retracted position.

\section{B. Significance of the Study}

This study goes through specific information about the usage of AOA sensor in aircrafts and the implementation and significance of MCAS system. Performance analysis of the system is done on the basis of the commercially purchased aircrafts by different flight companies and the analysis of the flights which are involved in accidents. The analysis will help us understand the AOA sensor parameters, critical pitch, speed indicators, algorithms involved and what can be done to address the issues concerning 737 Max 8 System. Boeing has stopped deliveries of all Max 8 aircrafts as of March 2019, while Software updating is ongoing for the MCAS System. The case study on the basis of Lion air JT610 and Ethiopian air ET302 aircraft is also done in the present study.

\section{Scope and Limitations}

The study is conducted with reference to Boeing Max 8 aircrafts currently in use which was commercialized since 2016. The scope of the study is to further understand the significance of the angle of attack, horizontal stabilizer and MCAS system automation etc. The main challenge in the study is to get relevant and pertinent data related to the flights that were operated by Boeing new generation Max 8 aircrafts. The case study analysis can reveal information on the flight data recording information's published and other official enquiry reports

\section{THEORITICAL AND CONCEPTUAL FRAMEWORK}

The study focuses on the performance of AOA sensor in Max 8 flights and associated Maneuvering characteristics augmentation system (MCAS System). Like many systems Boeing Max systems have many redundant systems.

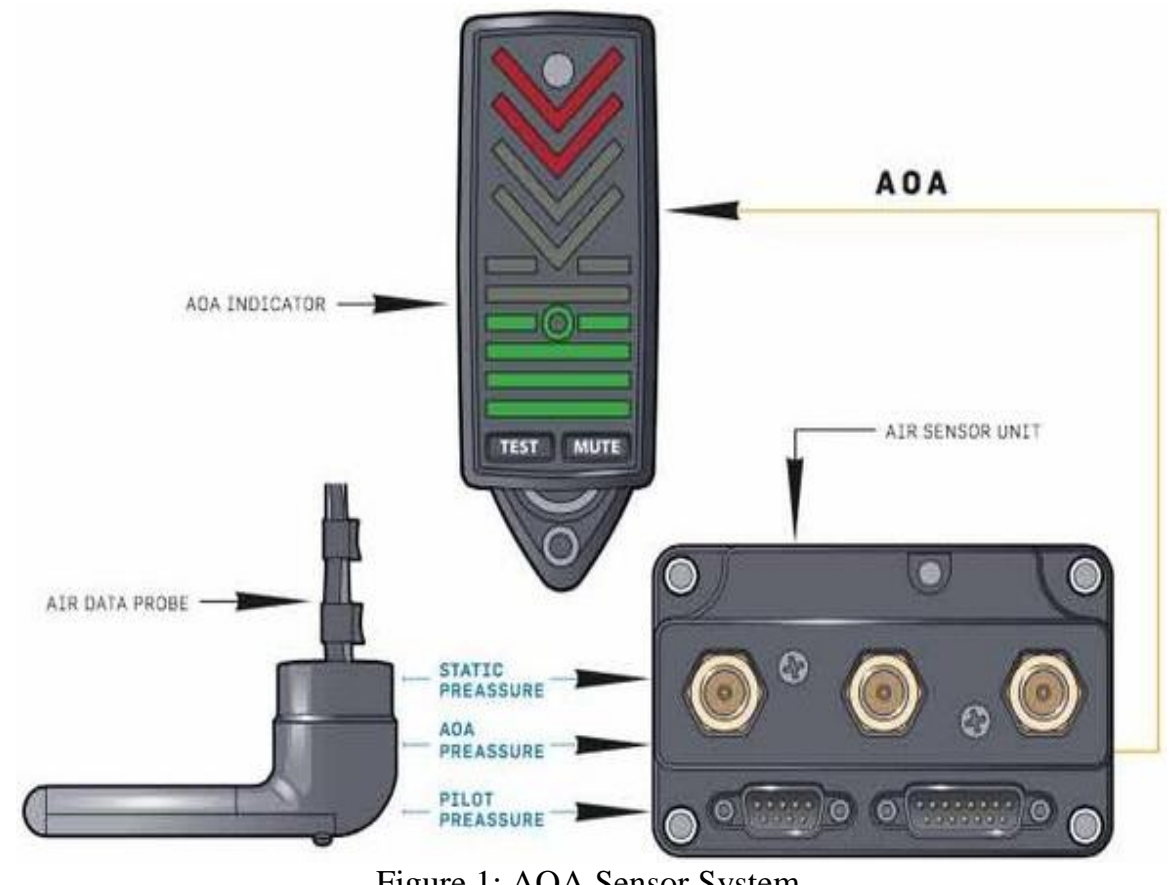

Figure 1: AOA Sensor System

AOA Sensor gives a general indication of the amount of lift acquired by the wing of the plane at a particular air speed or wind speed. Angle of attack is created along one of the two systems which might be either Lift reserve indicator or a normalized AOA. The sensor is normally coupled with a computerized system with a visual indicator at captains deck. 


\title{
International Advanced Research Journal in Science, Engineering and Technology
}

\author{
Vol. 6, Issue 5, May 2019
}

\section{A. Case Study on Lion Air Flight JT610}

During the course of the flight a malfunction in the sensor was detected in the cockpit as an IAS Disagree signal, which clearly indicates faulty readings. The Boeing cockpit has complex redundancy features and the in-flight system composed of 3 in-flight computers and digital panels which monitor different readings working parallel to each other. In this particular flight the erroneous data seems to be arising from the left side devices. So the practical and logical thing to act next is to rely on the right side data readings. After the take off was completed and retraction of the flaps, the aircraft was trying to achieve the optimal climb to reach the cruising altitude, but the aircraft refused to climb, pitching the nose of the aircraft in downward direction, it was counter acted by the flight crew by flicking a switch in the right side. But the aircraft continued to pitch the nose down at least 28 times in the 8 minute time interval which is a high frequency.

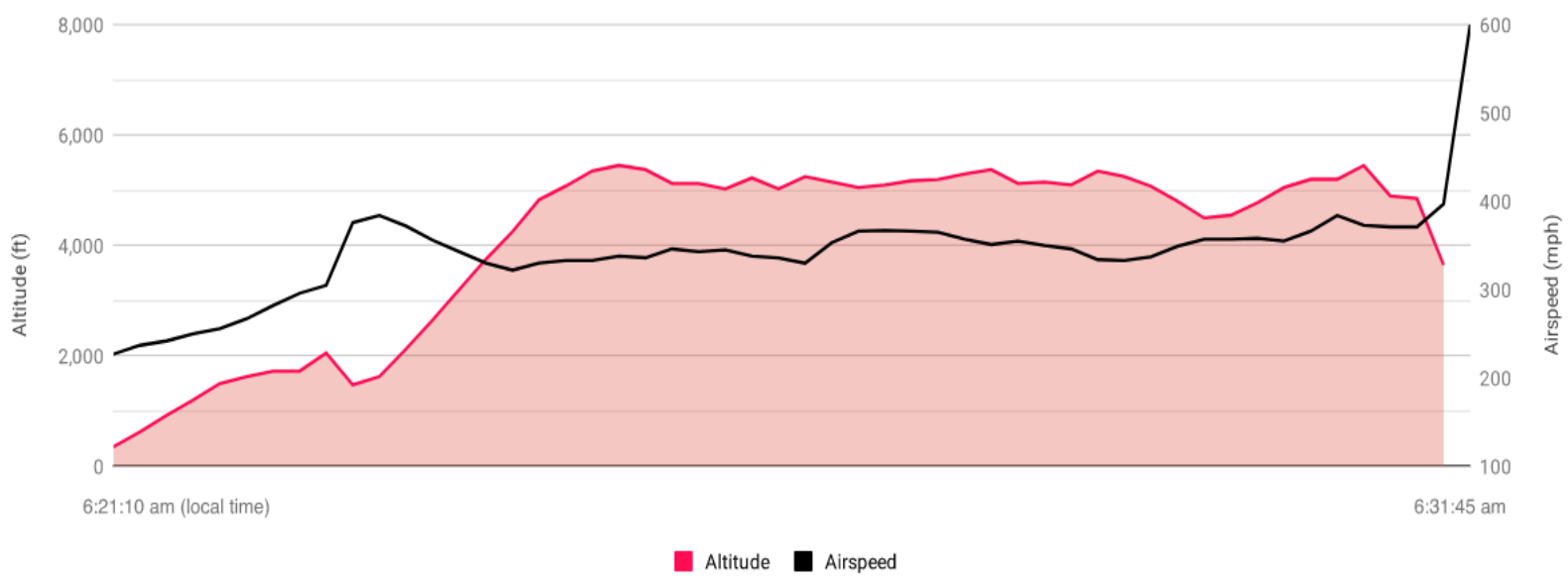

Figure 2: Flight data of JT610

Erratic altitude reading can be seen in the flight path (as shown in figure 2) after completing the take off procedure reaching $2000 \mathrm{ft}$ the cruising altitude procedure was initiated and around $5500 \mathrm{ft}$ was achieved and fluctuates between $5500 \mathrm{ft}$ to $4000 \mathrm{ft}$ during the period of approximately 25.5 seconds, the aircraft was pitching its nose down. As far as the air speed is concerned at a particular point air speed reached around $475 \mathrm{mph}$ at very low altitude before reaching the cruising altitude. Final recorded air speed reading was around $600 \mathrm{mph}$ which is the rate at which the missiles are shot.

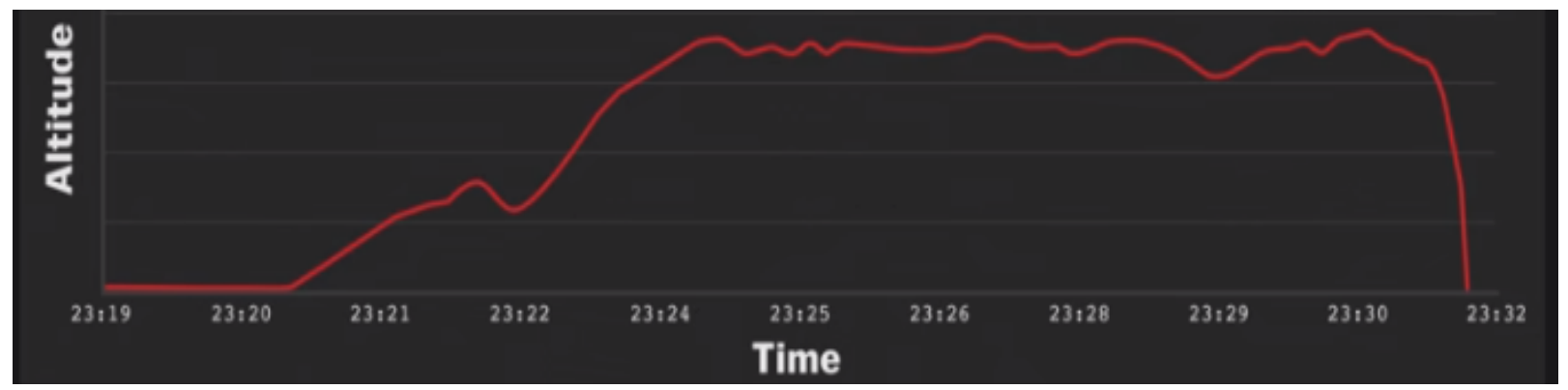

Figure 3: Altitude- Time Graph of JT610

In the case of data shown above, in the figure 3, it is clearly given at time around 23:22 the nose of the plane came downwards which was controlled by the pilot. The lurching of the nose down were repeated 3 times between 23:24 to 23:26, two times between 23:26 23:28 and two times \& one final dive between 23:28 and just at 23:32 around the time of crash. The above pattern clearly indicates that the nose down command was activated multiple times in the flight.

\section{B. Case study on Ethiopian Airlines ET302}

In Ethiopian airlines the left angle of attack sensor was giving high erroneous reading. The climbing rate was very less which leads to the MCAS activation as the flaps were retracted. A difference in AOA sensor reading will indicate faulty altitude level and speed levels in the left side of the cock pit. As the flaps are retracted the MCAS system trims the nose of the aircraft down. Pilot can override this trimming down by manually trimming up from the cock pit. But with a 10 second delay after overriding the trim down, the trim down is reactivated by MCAS. The Jack screw associated with the horizontal stabilizer system which trims the nose of the air craft down was found in a full nose down angle. At a very 


\section{International Advanced Research Journal in Science, Engineering and Technology}

Vol. 6, Issue 5, May 2019

high speed of the aircraft above 350 knots the horizontal stabilizer manual trim might be jammed and it is non operational. As in the flight data recorder readings at about $1000 \mathrm{ft}$ the left stick shaker is activated

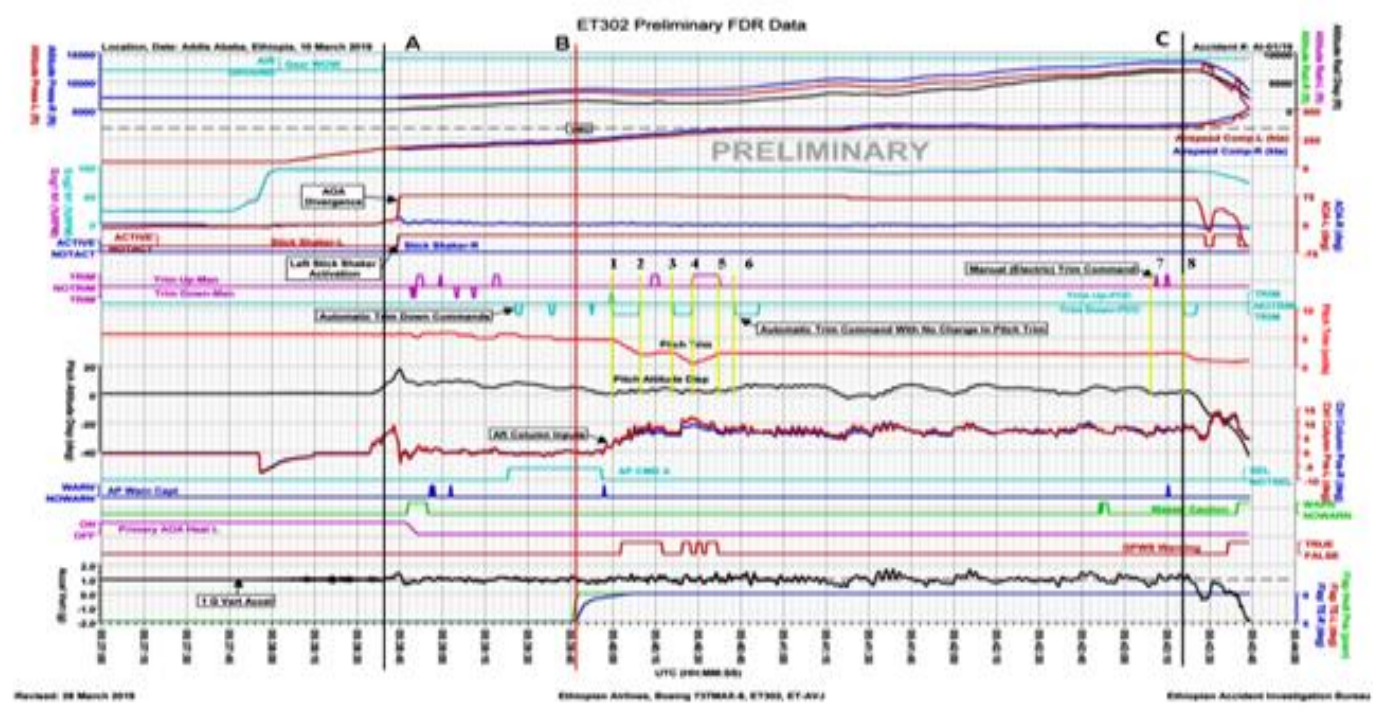

Figure 4: Flight data of ET302

\section{Analysis of the AOA Sensor performance}

AOA sensor points and tries to align itself to the incoming airflow. The angle of attack is an angle measured between the wing of the airplane and airflow. If the angle of attack is very high the MCAS system kicks in suggesting there is an impending stall. The kicking in of the MCAS is on the basis of this angle of attack data fed into the flight computer. Flight computer utilizes data from one of the AOA sensors either in the left or right. So if there is an erroneous reading the MCAS can be automatically kicked in. According to the records available from FAA USA, AOA sensor problems were detected on 216 flights operated in USA and 42 of them were from the Boeing airplanes. Clearly in both cases erroneous reading of AOA sensor was detected in the left side. In both cases, there were problems with the indication of air speed and altitude which was contributed by the faulty AOA sensor. In the case of JT610 the AOA sensor was replaced because of the persistent problems but even after replacing the problems continued.

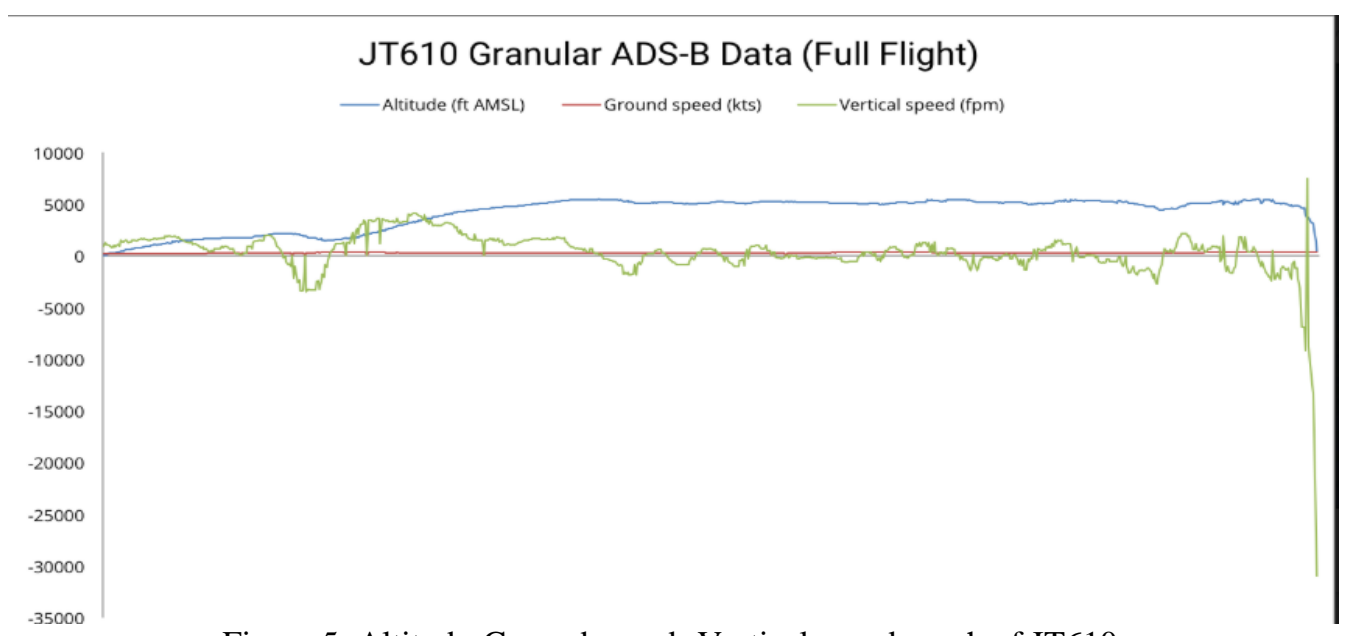

Figure 5: Altitude-Ground speed- Vertical speed graph of JT610

AOA sensor error is clearly indicated in the above graph .The above graph clearly gives a flight data recorder reading of JT610. The green colored indicated graph points out the erratic reading of vertical speed. A gradual variation in altitude is also indicated in the graph. In ET302 during takeoff the AOA sensors on both sides begin to malfunctions. The Left side AOA decreased to 11.9 degrees and then increased to 35.7 degrees at the same time the AOA on the right side indicated 14.94 degrees. Within the fraction of seconds the left AOA reaches 74.5 degrees and the right AOA was at 15.4 degrees. 


\section{International Advanced Research Journal in Science, Engineering and Technology}

Vol. 6, Issue 5, May 2019

D. Final Analysis of Cases

\begin{tabular}{|l|l|l|}
\hline Data/Machinery & JT610 & ET302 \\
\hline AOA Sensor & $\begin{array}{l}\text { Erroneous reading from start till } \\
\text { the end }\end{array}$ & $\begin{array}{l}\text { Erroneous reading from the start till the end on } \\
\text { both sides }\end{array}$ \\
\hline MCAS System & Activated more than 5 times & Activated multiple times during the flight \\
\hline $\begin{array}{l}\text { Deactivation of MCAS } \\
\text { system }\end{array}$ & Deactivation was not achieved & $\begin{array}{l}\text { Deactivation was achieved during the end time } \\
\text { close to crash by manually cutting of trim }\end{array}$ \\
\hline sensor error indicators & not installed & not installed \\
\hline Airborne timing & 12 minutes & minutes \\
\hline Type of the flight & Boeing 737 Max 8 poeing 737 Max 8 \\
\hline Pitch down command & Activated multiple times & Activated multiple times \\
\hline Reengaging of MCAS & $\begin{array}{l}\text { Reengaging was persistent } \\
\text { multiple number of times }\end{array}$ & $\begin{array}{l}\text { Reengaging was persistent multiple number of } \\
\text { times }\end{array}$ \\
\hline Safety procedures followed & Not clear & Followed Boeing manual procedures correctly \\
\hline $\begin{array}{l}\text { Flight control computer } \\
\text { input of sensors }\end{array}$ & $\begin{array}{l}\text { Received input from one of the } \\
\text { sensors }\end{array}$ & Received input from one of the sensors \\
\hline Altitude attainment & Difficulty in climbing observed & Difficulty in climbing observed \\
\hline
\end{tabular}

\section{CONCLUSION}

On the basis of the analysis conducted, it can be concluded that the MCAS activation criteria has to be revaluated. Activation on the basis of a single AOA sensor is very critical as the malfunctioning of any of the sensors can adversely affect the performance of the plane. In addition to this AOA sensor malfunctioning was reported a number of times for the fleets operated in US alone, which was not considered for overview even after JT610 incident, which can be critical. It was found out that the crash features of both crafts can be attributed to the erroneous AOA SENSOR which activated the MCAS System and consequently brought the mentioned flights down. There were similar patterns seen in flight time, pitch down command and activation and reactivation of MCAS in the corresponding flights JT610 and ET302. . On the basis of the analysis conducted the probability of involvement of faulty AOA readings together with the angle of attack readings contributed to the accident and a disagree signal indicator or the revisions in MCAS which includes the inputs from both the AOA sensors which consider the error factor can also be considered.

\section{REFERENCES}

[1]. Jon Ostrower "What is Boeing 737 Maneuvering Characteristics Augmentation System” Air Current Aviation Safety, November 132018

[2]. Darryl Campbell” The many human errors that crashed Boeing 737 max's" The verge, May 22019.

[3]. Zach Wichter" What you need to know after deadly Boeing 737 Max Crashes", May 24, 2019

[4]. User Manual of AOA System

[5]. Andrew J Hawkins" Everything you need to consider about Max 8 Crashes".

[6]. FAA Reports of Boeing Air worthiness, https://www.faa.gov/regulations_policies/airworthiness_directives/

[7]. Accident reports of JT610 and ET302, https://reports.aviation-safety.net/2018/20181029-0_B38M_PK-LQP_PRELIMINARY.pdf

\section{BIOGRAPHIES}

Minu Theresa Mathew received the B.S. and M.Sc. degrees in Electrical Engineering from Mahatma Gandhi University and Anna University India in 2009 and 2012 respectively. She has done extensive research in power electronics and renewable engineering field. She is now working in AMA International University /Bahrain

Associate Professor, Dr. Zeyad M. Ismail, B.Sc.(1973) in electrical power Received from University of TechnologyIraq. M.Sc.(1978) in Electronics and Communication from University of Baghdad-IRAQ. PhD.(1986) degree in power electronics from Loughborough University-UK.. He held several positions as dean and department head in different universities. Supervised many applied projects (R\&D) for the MoD in the field of power electronics and controller. He has supervised many $\mathrm{PhD}$, M.Sc. and undergraduate students. His recent research field of interest is in sustainable energy. He is recently working in the College of Engineering- AMA International University /Bahrain 